\title{
Poetizar o la superstición necesaria del lenguaje
}

\section{To poeticize or the necessary superstition of language}

\author{
José Antonio Santiago Sánchez \\ Universidad Complutense (Madrid) \\ litodav@gmail.com \\ ORCID iD: https://orcid.org/0000-0001-7789-0716
}

\section{RESUMEN}

Este artículo trata de teorizar sobre el lenguaje y, en su modo más aquilatado, el lenguaje poético, proponiendo unas bases inmanentes y enteramente prácticas, e incluso vitales en su sentido más adaptativo, a partir de ciertos conceptos como habitualidad y habitabilidad (Juan Bautista Fuentes) ritornelo (Deleuze), kairós, mimesis y poiein (provenientes de la tradición griega) o Stimmung (Heidegger) en las que se enmarcan los conceptos finales de Belleza y Verdad. Ello a su vez, obliga a distanciarse de una teoría de la poesía más visionaria o metafísica, así como a postular el lenguaje, sea este poético o no, entendido como «superstición» de la realidad.

Palabras Clave: habitualidad; habitabilidad; ritornelo; kairós; Stimmung; superstición; mimesis; poesía.

\section{ABSTRACT}

This article attempts to theorize about poetry, proposing a immanent and entirely practical basis, and even vital in its most adaptive sense, from certain concepts as habituality, habitability (Juan Bautista Fuentes), ritornelo (Deleuze), kairós, mimesis and poiein (from the Greek tradition) or Stimmung (Heidegger) in which the final concepts of beauty and truth are framed. This, in turn, requires to grow apart from a visionary and metaphysical poetry, and to apply the language, be it poetic or not, understood as "superstition" of reality. Poetry.

Key words: Habituality; Habitability, Ritornelo; Kairós; Stimmung; Superstition; Mimesis; 
Estamos tal vez aquí para decir: casa, puente, surtidor, puerta, cántaro, árbol frutal, ventana, todo lo más: columna, torre... pero para decir, compréndelo, oh para decir así, como ni las mismas cosas nunca en su intimidad pensaron ser (...) aquí es el tiempo de lo decible, aquí su hogar.

R. M. Rilke: Elegías a Duino.

I. «Nunca estaremos en condiciones de decidir si vivimos la infinitud como prisión o como libertad», señala László Földényi (2008: 77) en su libro sobre la melancolía.

Con esta humilde duda — pues tal vez no todas las dudas sean humildespodríamos comenzar: la poesía, este «árbol sin hojas que da sombra», al decir de Juan Gelman, ha intentado ser comprendida desde los albores del logos en la Grecia Antigua como una dimensión especial del mismo. Y de arboladas, sombras y cobijo querríamos hablar, más que de infinitud.

Suele decirse, así, que todo empieza con la pregunta.

Una pregunta, movida por la admiración ante el mundo de lo que está ahí y en cuya reconocida extrañeza, no solo el poeta, sino cualquiera que esté vivo y atento a lo que sucede en efecto, se hace de modo inhóspito, como recién arrojado por momentos. La extrañeza, sí. Y sin embargo, «tenemos lealtades — señala Chesterton (2013: 87) — antes de tener admiración». ¿Por qué —entonces - la poesía, el poema, más que una búsqueda de una realidad «que siempre está en otra parte» no es primeramente un suelo sobre el que preguntar, una necesidad, justamente inversa, de enraizarse ante lo extraño que nos desfundamenta?

¿No hay que estar vivo antes? ¿Y no es estar vivo situarse ya en un lugar y un tiempo, ante los otros? Resulta por momentos tan peregrino y a la vez tan vacuo y vano hablar de Mundo, Infinito, Soledad... ¡Ah! La soledad del poeta. César Vallejo (1998: 535) dice en unos versos lo siguiente: «Alguien limpia un fusil en su cocina. / ¿Con qué valor hablar del más allá? (...) Otro busca en el fango huesos, cáscaras, / ¿Cómo escribir, después, del infinito?».

Pues como Empédocles señalara hace siglos, Apolo y asimismo el resto de los dioses, a diferencia de los humanos, con un «un corazón sagrado e inefable (...) se lanza a través del mundo entero tirando flechas», ya que «en sus miembros no está provisto de una cabeza semejante a la del hombre, ni de su dorso parten dos brazos, no tiene pies ni rodillas veloces ni genitales vellosos» (B, 134). Los sentidos humanos actualizados a través de sus miembros tienen una proyección limitada, el mundo circundante es aquel al que dichos sentidos alcanzan.

Lo primariamente verdadero es que somos. Este rizomático modo de ser se establece primariamente desde una finitud. Luego llega la pregunta. Pero antes 
está la obvia y delimitada facticidad del que está preguntando. ¿Con qué derecho hacer epojé de lo que ya es para advertir lo que se busca? La pregunta por el fundamento ha de comenzar constatando lo concreto e irreductible que siempre ya se es antes de quebrarlo con la pregunta que no deja de ser, asimismo, también irreductible condición de ser lo que somos. Sin la pregunta, no hay horizonte. Sin horizonte, no hay sentido. ¿Preguntarse por el todo... desde dónde?

De nuevo Empédocles:

Porque los sentidos esparcidos por los miembros tienen reducido alcance (...) Y en sus vidas solo experimentan una mínima parte de la vida, y siendo de la composición del humo, mueren y se esfuman rápido, convencidos única y exclusivamente de aquello con lo que cada uno de ellos se ha topado en sus múltiples peregrinaciones, y sin embargo, cada cual se vanagloria de haber encontrado el todo $(\mathrm{B}, 2)$.

Extrañeza o admiración respecto a lo que hay. Esa es, según Aristóteles, la condición natural del hombre. Y sin embargo, decimos, ¿no se vuelca el jarrón de las Dánaes demasiado pronto? Por eso, la duda por momentos se encuentra capciosamente vacía de concreción, tiempo y lugar. Esa duda... tan metódica y sugestiva: ¿Por qué el Ser? Tal vez olvide que el conocer, ya desde Platón, es reconocer y reconocerse. ¿Cómo hacerlo entonces desde esa nada que pregunta tan fuerte?

Pero los vivos cometen

todos el error de distinguir con demasiada fuerza (Rilke 1998: 65).

Así pues, la poesía, desde su fastuoso germen iniciático, se concibe como la búsqueda de lo otro, como un deseo de alcanzar esa respuesta que la extrañeza de vivir se impone en nosotros, los humanos, de modo tan esencial. Y el poeta, entonces, señala Rimbaud, sería el vidente, esto es, aquel que descubre esa verdad oscura, mortal y cifrada que las palabras de la tribu no pueden comprender en su trasiego de troqueladas palabras. El poeta, señala Nietzsche - o el filósofo - se atreven a constatar la memoria de unas metáforas cuyo continuo uso ha ido gastándose en olvido. $\mathrm{Y}$ al hacerlo, proyecta a la cara oculta de luna el misterio de que siempre hay algo más que tiene que decirse, o bien, que se puede decir de otro modo. «Materialidad de lo utópico como energía de presente», lo consigna Miguel Casado (2009: 26), al hablar de la experiencia poética.

II. Si viniera un hombre,

Si viniera un hombre al mundo, hoy, con

la barba de luz de

los patriarcas: él, 


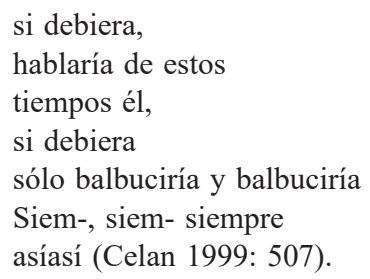

Son versos - el lector atento lo habrá identificado - pertenecientes al poema Tübingen. Jänner de Paul Celan. Siguiendo el hilo de estos versos, tomamos para continuarlo a uno de los más conspicuos herederos rimbaudianos en busca de ese espíritu vidente de la poesía, Martín Heidegger.

Para Heidegger, el poeta sería el vate que está llamado a la tarea de profetizar los tiempos por venir, una vez proclamada la muerte de Dios, del Horizonte y del Fundamento tras los desastres de la Modernidad occidental. Pero este mensaje no es entendido, como así parece mostrarlo el poema de Celan.

El poeta, desde Baudelaire, es un genio incomprendido, un anunciador que farfulla palabras ininteligibles para el idioma común, que propugna, como el oráculo, la palabra que ha de advenir de modo cifrado, enigmático. Son evidentes los ecos románticos en esta consideración del arte poético. Como señala Rimbaud (1995: 123), «nunca se ha entendido bien el romanticismo [...] Los primeros románticos fueron videntes sin advertirlo del todo».

El poeta entonces, aparece como el gran maldito, el loco que anuncia la verdad a los que no tienen oídos para escucharla. Su figura es la de un profeta solitario de los tiempos por venir, el nuevo patriarca que inaugura en el desierto un nuevo pensar, un nuevo horizonte: «porque les hablé, pero no escucharon, y los llamé, pero no respondieron» (Jer. 35: 17). La tarea del poeta, ominosa por solitaria, genial por incomprendida, se erige continuadora del apóstol o el profeta. Así lo sostiene Rimbaud (1995: 113-114):

Digo que hay que ser vidente, hacerse vidente. El poeta se hace vidente por un largo, inmenso y razonado desarreglo de todos los sentidos. Todas las formas de amor, de sufrimiento, de locura; busca por sí mismo, agota en sí todos los venenos, para no quedarse sino con sus quintaesencias. Inefable tortura en la que necesita de toda la fe, de toda la fuerza sobrehumana, por la que se convierte entre todos en el enfermo grave, el gran criminal, el gran maldito, - iy el supremo Sabio! - ¡Porque alcanza lo desconocido! ¡Porque se ha cultivado el alma, ya rica, más que ningún otro! Alcanza lo desconocido y, aunque, enloquecido, acabara perdiendo la inteligencia de sus visiones, ¡no dejaría de haberlas visto! Que reviente saltando hacia cosas inauditas o innombrables: ya vendrán otros horribles trabajadores; empezarán a partir de los horizontes.

Misión sagrada. La poesía heredera de la religión tras la huida de Dios. El poeta «lleva el peso de la Humanidad sobre sus hombros» (Rimbaud 1995: 121). Pero los hombres, en tiempos de miseria, no quieren escuchar, engolfados 
en sus falsas conciencias, en sus vanas fruiciones. Por eso, al igual que Celan hacía de Hölderlin el profeta del balbuceo en los tiempos actuales, Heidegger recupera los versos del poeta suabo, y los convierte en todo un lema de la poesía a partir de la segunda mitad del siglo XX: «¿para qué poetas en tiempos de miseria?» (Heidegger 2010: 199-238).

Hallar un nombrar nuevo, visionario. He aquí el riesgo del poeta, su tragedia. Volver a robar el fuego a los dioses. Reencontrar lo humano en el nominar, vislumbrar al Dios que aún puede salvarnos a través de la poesía y sus vates. Favorecer el espacio del Ser en la penuria del logos humano que en los tiempos de miseria se encuentra por doquier y constantemente instrumentalizado por la racionalidad de los medios-fines. «Todo funciona - señala Heidegger- Esto es precisamente lo inhóspito que todo funciona y que el funcionamiento lleva a más funcionamiento y que la técnica arranca al hombre de su esencia y lo desarraiga» (Heidegger 1989: 71).

Por ello, ante tal positividad instrumental de lo que siempre se encuentra no tanto ante el hombre, sino para el hombre, el poeta, en su ingente tarea, debe realizar una labor sagrada de purga o vaciamiento del logos instrumental. Esta labor, heredera, de nuevo, de la religión mística occidental, establece una parada significativa entre palabras y cosas. Su tarea consiste, por tanto, en «transfundir de nada» ${ }^{1}$ el lenguaje, ralentizar, distender e incluso abortar la semántica, «demasiado humana», de las metáforas. En el contexto del nuevo logos hiperfuncionalizado por los modos masivos de la comunicación e información instantánea que, como una suerte de armonía preestablecida leibniziana se despliega como una red homogénea y ubicua de compenetraciones recíprocas a través de los individuos-mónadas felices y autosuficientes (Lynch, 2010: 97) el poeta debe, como Yaveh hizo en Babel, desestructurar dicha concepción del lenguaje, obliterar su fácil accesibilidad, desdimensionar su inmediatez. De este modo, el lenguaje del poema debe ser cifrado, enigmático.

El fundamento de este enigma se encuentra justamente en su vuelta, a través del poeta, de la capacidad proyectiva y posibilitadora del logos. Frente a la tradicional concepción del lenguaje científico, determinante y positivista, cuyas formas mundanas desembocan en el lenguaje de los mass media y la ultracomunicabilidad, el logos poético propone insertar una suerte de lo que José A. Valente (1974: 17) llamaría «vacío fértil». En este papel quasigenésico de la nada, la palabra poética permite, según esta visión, tomar el pensamiento de un modo verdaderamente poético por cuanto su naturaleza huye de la jaula empírica dentro de la que el logos ortodoxo ha sido recluido. Recuperar el valor de la palabra en su sentido más cultual a través de la nadificación, esto es, de la cerrazón mística (del verbo griego myo: «cerrarse») por un lenguaje

${ }^{1}$ Se trata de un verso del poema Wirk nicht voraus de Paul Celan (1999: 349), traducido y muy apreciado en este aspecto que aquí tratamos por José A. Valente, del que se hablará a continuación. 
que desborde la determinación plana e inmanente del otro lenguaje cotidiano y científico, un lenguaje encapsulado que es preciso romper. $\mathrm{Y}$ ha de hacerse cerrándolo en sí mismo para abrirlo a eso que Heidegger llamaría un nuevo «nombrar fundador». Un nombrar que deje ser a las cosas, a la realidad misma como lo que es.

Pero además, como el místico, debe hacerlo, tomando la nada desde la perspectiva más genuinamente creativa. Situar en el vacío de las significaciones cotidianas lo no dicho y siempre aún por decir: establecer un nuevo modo de pensar a través de un nuevo lenguaje. Así, al modo judeocristiano de la creatio ex nihilo, solo el vacío proyectivo inoculado por la poesía en las palabras de la tribu, es decir, solo el enigma del vidente-poeta permite trasladar el lenguaje - verdadera y única carne del logos humano - a esa, si no trascendencia, sí proyectividad, potencia o capacidad en lo cual Miguel Casado sitúa la clave de la experiencia poética: el deseo de salir, lo «exterior». La poesía como esa búsqueda de misterio insondable, nunca expresable sino tangencialmente. Búsqueda de un más allá que la pregunta abre y que no puede decirse de modo normalizado: necesidad de apertura y ensoñación. Un «yo» solo, cuyo afuera es un sueño, ocupa el alma. La realidad está en otra parte.

III. Y sin embargo, hay algo que en toda esta concepción, parece escaparse de un modo excesivamente vaporoso. Como los escorzos de un Laocoonte al que le han privado de las serpientes y queda así en un gesto vaciado, un mero molde, una expresión clueca.

Por ello el fundamento de la poesía, como del arte en general y aún más, de toda labor productiva en su sentido más prístino se antoje tal vez distinta e incluso más bien, anterior a este pensamiento poético respecto al cual tal vez urge un nuevo origen. E incluso, de un origen aún no establecido, situado en la inmanencia y no tanto en la trascendencia de lo exterior. Un lenguaje definido en la ruptura de los férreos límites en los que necesariamente, nos determinamos. Y tal vez, de nuevo, se nos pueda permitir aquí, y a partir de ahora, una nueva exposición.

Y decimos exposición en un doble sentido: en primer lugar porque frente a la exposición bien instaurada del pensamiento anteriormente «expuesto» acerca de la poesía o el «poetizar», esta otra no puede ser, en segundo lugar, sino una otra exposición que a su vez, se sitúa «ex-puesta» como un planteamiento que está — quizás - por descubrir, sujeto al desacoplamiento o imbricación de la visión anterior, y por tanto, susceptible también a las consecuencias objetivas que en cuanto finis operis pueda tener posteriormente. En cuanto a la pretensión subjetiva o finis operantis, la intención es situarla no tanto en un lugar contrario, sino más bien, nos atrevemos a decir, más originario y simple. 
IV. Todo el que ha compuesto, contemplado, leído o escuchado una obra artística verdadera (y asimismo una «verdadera obra» artística, es decir, cerrada, completa o perfecta) parte de una sensación o conocimiento que resulta - creemos - similar en el emisor y receptor. Se trata de una experiencia que podríamos llamar de «conjuración» y cuya recepción o composición podrían ser descritas junto a la tradición platónica, como «reconocimiento».

Nos atreveríamos a decir que la primera experiencia, tanto sensible como intelectual que se tiene al leer o escribir un gran poema u obra artística es aquella que lo percibe y conoce como algo en lo que varias líneas biográficas, imágenes, tiempos y modos lingüísticos y situacionales convergen en una suerte de momento propicio. Se trata de que el verdadero poema, y el poema verdadero, está «dicho y hecho» en un momento y lugar claramente limitados. Lo dicho y hecho, por tanto, aparece, tanto física como inteligiblemente completos respecto del momento y lugar en que se escriben o se leen. Esta doble experiencia - llamémosla interior y exterior para seguir con este tradicional y ambiguo dualismo - de que es «justo aquí y ahora» que lo dicho y lo leído tenía que decirse y leerse se produce justamente porque esta conjuración desvirtúa en sus límites lo leído o «interior» frente a lo dicho o «exterior». El tiempo de lo dicho justo en el momento oportuno es el pretérito perfecto simple o compuesto que tanto abunda, por ejemplo, en la poesía de Antonio Gamoneda: «Lo leí». «Lo ví». «Esto me fue dicho».

Asimismo, la referencialidad lingüística del poema determinado y completo en su per-fección — pues no existe significatividad sin referencia- no es la subyunción a otros poemas o composiciones. Su sintaxis es más bien paractáctica: tras lo dicho y hecho hay, habrá, otros tiempos y lugares homologables en sus palabras, tiempos o modos respecto a ello, pero nunca identificables. Tiempo de lo perfecto indicativo, de lo completo y cerrado. La determinación, a fin de cuentas, de la que aquí se habla se antoja bien distinta de esa jaula de la experiencia que el decir del poema quiere trasvasar. Pues dicha jaula primeramente y antes de ser experienciada como angustiosa o falta de algo, es decir, antes de vivirse como una prisión no es sino la propia circunstancia de nuestra limitada experiencia mundana. ¿El mundo es una jaula de experiencias o es el mundo, y una jaula de experiencias? ¿Y de donde proviene toda duda o pregunta, toda proyección sino de esa determinación contingente de nuestros sentidos, sin ese cerco o límite necesario de la circunstancia humana?

Así lo confiesa Chesterton (2010: 205):

Durante toda mi vida me han maravillado los filos, y la línea de delimitación que reúne bruscamente una cosa junto a otra; toda mi vida me han encantado los marcos y los límites, y opino que el paisaje más grande y más salvaje parece mayor contemplado desde una ventana. 
Esta primigenia experiencia de conjuración que se experimenta en la composición o lectura de un poema verdadero y de un verdadero poema, poco o nada tiene que ver, en un primer momento, con el desbordamiento o la exterioridad proyectiva del lenguaje. Al contrario, se trata de una contracción de líneas vitales de diversa índole que se conjugan y cierran de modo completo en un momento clave, decisivo y que tanto el poeta como el lector experimentan como necesario. Lo dicho y hecho (facio) por (per) el poema en su completud per-fecta se im-pone entonces a la hora de experienciarlo. «Si digo lo que digo es porque me ha vencido lo que digo», afirma Antonio Porchia (1975: 66). Lo dicho y hecho se imbuye de una necesidad. Esto tenía que decirse. Y tenía que decirse — decimos - justo aquí y justo ahora.

En este sentido, los vocablos «poesía» o «poema», Dichtung, Gedicht en alemán, apoyan esta experiencia de conjuración por cuanto que lo dicho y hecho resultan de una ajustada y completa connivencia o densificación (en alemán dicht significa «denso»), no tanto por la materialidad puramente semántica o sintáctica de sus palabras, sino por cuanto a su hacer (facio) conjurado de todas estas múltiples líneas de fuga de carácter diverso que confluyen $a$ través de (per) y en el poema.

V. Dicho lo cual, conviene reconvenir a esa gran figura de la «Creación» poética. E incluso más, es preciso resituar el omnímodo y sagrado lema de la «libertad creadora».

Como se sabe, ambos conceptos, creación (ex nihilo) y libertad creadora, provienen esencialmente de la teología y cosmogonía judeocristiana. El pensamiento griego, a lo largo de toda su trayectoria, fue totalmente ajeno a concebir una idea de Creación. Pues la creación, por definición, supone la nada previa desde la que se «in-venta», como lo que viene (venio) «desde dentro» (in) del Creador - esto es, desde su nada - en la materia y forma de lo creado. ¿Cómo hacer surgir algo de la nada? Ningún dios, por muy poderoso, podría lograr ese límite ex nihilo desde el cual generar algo. La Creación, como la duda pura, o la pregunta prístina, está supuesta de una especie de omnipotencia, de absoluto o indeterminación categóricamente opuestos a toda obra artística.

Sin embargo, como señala Hans Jonas (1998: 161) respecto a ello, la propia consecuencia del poder creativo supone en Dios una suerte de limitación. La omnipotencia, continúa Jonas, «es un concepto contradictorio en sí, que se anula a sí mismo y que resulta absurdo» (Íbid.). Su situación es la misma que la de la libertad en el ámbito humano. Lejos de que esta comience al desbordar la necesidad natural, la libertad precisa justamente medirse con la necesidad. Este dualismo, tan apostado en la estética y la filosofía del arte desde Kant, y sublimada en el Romanticismo, entre el Reino de la Necesidad y el Reino de la Libertad, acaso reconfigurado contemporáneamente en la famosa dicotomía entre la Vida y el Arte, intenta ser desmontado por Jonas a partir de su análisis 
de la teología judeocristiana, de la que en el fondo — como decimos - esta distinción parte.

Según Jonas, al separar la libertad (creadora) del reino de la necesidad, se priva a aquella de su objeto sin el cual se vuelve tan nula como la fuerza sin resistencia.

La libertad absoluta sería una libertad vacía que se anula a sí misma. Lo mismo vale también para el poder, que sería vacío si fuera absoluto y único. Poder absoluto y total significa un poder que no está limitado por nada, ni siquiera por la existencia de algo otro en general, algo fuera de él mismo y distinto de él. Porque la mera existencia de algo otro representaría ya una limitación, y el poder único debería aniquilarlo para conservar su carácter absoluto. Entonces el poder absoluto, en su soledad, no tendría ningún objeto sobre el que pueda ejercer su efecto, pero como poder sin objeto, un poder es impotente y se anula a sí mismo. «Omni» equivale aquí a «cero» (ibíd.).

Para poder generar algo es preciso un material previo y necesario. Para la Weltanschauung griega, no existe hombre ni dios que puedan, a partir de su palabra, formar algo desde la nada. Por ello, se trata más bien de configurar, componer y recomponer a partir de lo que siempre, a priori, nos es dado: humana y esencial labor de la territorialización a partir de los límites y hacia los límites.

De hecho, y como señala gran parte de la Cábala, si la Creación fuera aun así posible, esta debería concebirse menos como un proceso desbordante de límites y más bien como una contracción o retracción que fija los límites determinantes. El zimzum cabalístico que Gerschom Scholem ha trabajado con denuedo representa, no tanto una capacidad de agrandar o ensanchar (el término «autor» proviene del verbo latino augere que significa precisamente esto, «ensanchar») sino más bien la voluntad divina para dejar de ser absoluta en su obra determinante a partir del Ein-Sof o Infinito primigenio. De este modo, la Creación se describe para Scholem (1995: passim) más bien como una retracción o autodeterminación fundante en la que el Ein-Sof se reconoce en la delimitación creadora de la Obra.

VI. A esta conjunción de casualidades causales en un aura temporal y local, a esta experiencia cada vez más densa e hilada de inminencias que se van propiciando de modo perfectivo en la experiencia lectora y compositiva (y no tanto creadora entonces) de un poema hasta que este se concibe como algo en lo que tenía ser suceder justo así y justo ahora, a ese reconocimiento de lo oportuno, en definitiva, los griegos lo llamaron kairós.

Dije: Todo, completo.

¡Las doce en el reloj! 
Son versos del poema «Pleno ser», pertenecientes a Cántico de Jorge Guillén (2010: 103). En ellos se presenta esa experiencia poética como inminencia del presente completo. Los recuerdos, sonidos y toda brizna de realidad se convierten en inminencias convergidas en el poema como un presente per-fecto. $\mathrm{Y}$ este presente (praesens) es tanto un haber o ser (esse) que está ahí (prae) como, al mismo tiempo, un don a través de ese kairós que el poema ha hecho conjurar. El «presente» también, en su doble acepción, como «presente», es decir, como regalo. Todo completo: ahora lo veo. Ahora lo sé. Lo que está ahí me es regalado en esta confluencia oportuna y cerrada, en esta hora completa: las doce en el reloj.

Este presente conjurado me cobija en su ámbito, me tiene en su mano. En francés, el presente es la mano que te tiene, o mejor, que te «va teniendo» (maintenant). El poema, en su propio desarrollo, más que fugarse o lanzarse, se contrae en un fértil densidad (Dichtung) y en los que tiempo y lugar no tanto se tienen, sino más bien, se man-tienen. «Plausible conjetura», titulará posteriormente Guillén otro poema de Homenaje comenzando por la misma imagen y que conjura al mismo tiempo, todo lo dicho:

¡Las doce en el reloj!

El mundo es otro círculo.

¿Se me revela ahora

Su centro, su principio?

Todo es aquí planicie

Dorada por los trigos

Que espiga a espiga forman

El cuerpo de un estío

Con voluntad de ser

Un solo impulso erguido

Bajo el cielo atrayente

Desde ese azul.

Admiro

Con fervor de mirada

Convergencias y signos

De algo que yo, torpe,

Escruto y no descifro.

Y mientras mi ignorancia

Sigue curva de río,

Contemplo — fascinado-

La Creación en vilo

Suspendida ¿de qué,

De quién?

Atisbo Plausible conjetura

¡Ay, nada más, Dios mío! (Guillén, 2010: 2018). 
VII. Según Julián Serna Arango (2009: 54), los griegos establecían tres vocablos que conceptualizaban asimismo tres distintas experiencias respecto al tiempo: chrónos, aión y kairós. Dichas nociones no se confundían ni a la vez podían sustituirse entre sí. De tal manera que, si chrónos aludía al tiempo lineal registrado por el reloj y la clepsidra, aión era, en cambio, el tiempo de la vida y el tiempo subjetivo registrado por la memoria y la imaginación. Por último, kairós correspondía a la percepción y aprovechamiento del momento oportuno barruntado, por así decirlo, por la sensibilidad y la inteligencia tanto en su aspecto proléptico o proyectivo, como anamnético o rememorante. Así, conjugando aquello por venir, o bien trayendo en confluencia el pasado recordado, el kairós es la conceptualización noética de las doce en el reloj.

A partir de esta triple distinción, prosigue Serna Arango, chrónos se asocia al principio de la «sucesión», aión se resignifica como «simultaneidad» y kairós como «bifurcación». Esta última caracterización, para Serna Arango, establece el concepto de kairós a una suerte cambio de itinerario por parte del sujeto atento al momento oportuno, a la occasio (de ob y cadere, literalmente «caer o suceder enfrente»). La mejor representación visual de esta concepción se muestra en la escultura de bronce de Lisipo de Sición (370-318 a. C), llamada justamente kairós. Aunque la obra del que se dice que fue el escultor oficial de Alejandro Magno ha desaparecido, se nos ha legado en forma de varios relieves y constituye, según Serna Arango, una de las más sugerentes transcripciones escultóricas del concepto. En uno de los relieves conservado en el Museo di Antichità, en Turín (fig. 1), se muestra a un joven de cabeza calva a excepción

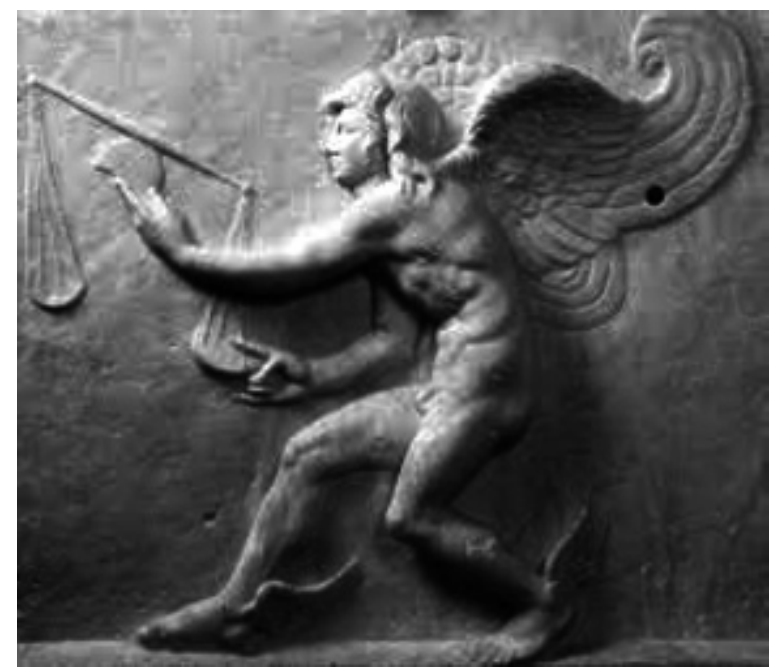

Figura 1. Fragmento de un sarcófago con la personificación del kairós.

Copia romana del original de Lisipo. Siglo II d. C. Turín, Museo di Antichitá. 
del mechón de cabello que cae delante de la frente. Tiene los pies alados a punto de correr y escaparse, lo que obligaría a quien lo persigue a actuar con precisión si quiere atraparlo. Asimismo, el muchacho aparece sosteniendo con su mano izquierda en equilibrio el asta de una balanza con la cuchilla de una navaja de afeitar, mientras el dedo índice de la derecha sujeta sutilmente uno de los platos del instrumento de medida para reestablecer el equilibrio «como una manera de advertir al observador que si actúa en el momento oportuno estaría en condiciones de cambiar el curso de los acontecimientos» (Serna Arango, 2009: 42-43). De eso se trata: tomar el momento oportuno es «cambiar» la circunstancia, y por ende, a uno mismo. Por ello, el muchacho se representa con un mechón de pelo delante como única cabellera, pues es preciso atrapar el momento oportuno de frente, antes de que nos dé la espalda, ya sea desde su ocasión futura o desde su recuerdo pasado. De ahí también el paremio «a la ocasión la pintan calva», pues es preciso «hacer caer» (cadere) activa y previamente el momento para llevarlo hacia $(o b)$ puerto (portus) o arribo cómodo y favorable, es decir, «oportuno» (ob-portus).

De este modo, el límite queda establecido. La poesía entonces no surge de una energía del presente que se proyecta hacia el horizonte o el misterio, sino que es el misterio mismo anclado al momento propicio.

A partir de esa oportuna determinación, se lanzan de nuevo las líneas que buscan una inminencia de algo más por llegar. Pero sin ese humus, sin ese límite primario de convergencias que habitúan a la realidad no puede proyectarse nada. Porque esas inminencias solo pueden suceder en un cerco presencial determinado, el territorio del aquí y ahora: la Dichtung o densificación. Este pensamiento del límite al que Eugenio Trías ha dedicado la mayor parte de su labor filosófica es el que aquí se trae a colación: la pregunta, la falta de sentido, la privación fértil, la proyección desde la cual lo no dicho siempre queda por decir, ¿no parte primariamente de un cerco, una retracción de circunstancias conjuradas? La propia comunicación poética ¿no se inicia a partir de una constatación, en su deixis espacio-temporal de la contingencia misma de que lo que se dice solo puede ser dicho en un momento y lugar que concita? ¿Cómo hablar del «exterior» sin un límite primario?

VIII. En este cerco preciso y contingente de la circunstancia - decíamos - es donde se desarrolla lo que bien podría llamarse la habitualidad y habitabilidad de estar ${ }^{2}$. Una habitualidad y habitabilidad originarias que sitúan y determinan

\footnotetext{
${ }^{2}$ Debo esta doble nombradía al profesor Juan Bautista Fuentes Ortega, cuyo despliegue y justificación, aún no publicadas, pueden ser conocidas en una mesa redonda sobre el pensamiento de Chesterton impartida el 24 de abril de 2007 en la Facultad de Filosofía de la Universidad Complutense y cuyo visionado puede hacerse en esta dirección electrónica: https://www.youtube.com/watch?v=-LTr606rERI.
} 
la circunstancia y sin la cual, como señalaba Ortega y Gasset, es imposible la existencia humana, ni siquiera la animal. No se trata de una mera cuestión «existencial», de una necesidad biológica, adaptativa.

En esta inercia del estar circunstancial, el humano, como el animal se ajusta progresivamente al territorio y al tiempo en él convergido, haciéndolos suyos y haciéndose con ellos. Los modos de dicho estar son muchos, pero su forma es esencialmente cíclica. La habitualidad no puede concebirse sino desde el modo de la repetición de lo mismo en un devenir siempre otro. Las estaciones, los ciclos vitales, la naturaleza entorno, las construcciones, las calles y sus esquinas, el hogar... todo lo que se conjuga alrededor en la habitabilidad habitual se concita determinante y a la vez contingentemente en el desarrollo vital de cada individuo. Es la forma del ritornelo. «El universo - señalan Deleuze y Guattari (2004: 307)— está hecho de ritornelos» El lenguaje, por supuesto, es un modo más de este entorno vital.

La territorialización adaptativa es aquella en la cual cada individuo heterótrofo nervado y vertebrado sitúa un cerco limitado por sus sentidos y comprensión y desde la cual este contrae y asegura la habitabilidad a través de la habitualidad y viceversa. No se trata, insistimos de una mera cuestión psicológica, sino biológica. Los animales marcan su territorio con orines, exudaciones u olores. Se trata de una conducta instintiva, establecida de un modo evolutivo en los genes. Los restos fisiológicos, las ultimidades biológicas se convierten en marcas, digamos, «metafóricas» en huellas residuales precisas con objeto de establecer un cerco de seguridad vital en cuyo límite se despliega la habitabilidad y habitualidad del territorio.

Pero también, señalan Deleuze y Guatari, esa territorialización se produce con los sonidos. Sonidos ritmados o repetidos con ciertas modulaciones. Los ritornelos toman la forma de cantos de pájaros, de voces al cortejo o llamadas al peligro de que algo puede desajustar el estar circunstante. Estas formas sonoras o musicales, que Aristóteles mentaba con el término griego phoné se distinguen del logos (Ética a Nicómaco 1170b) en cuanto a su modo sintáctico y semántico. En un texto célebre de la Política, el Estagirita sostiene que la «Voz» o «sonido» (phoné) «es signo del dolor y del placer, y por eso la poseen también los demás animales» para así indicársela a otros. Sin embargo, el lenguaje, cuya naturaleza es sumamente más articulada y compleja «es para manifestar lo conveniente y lo perjudicial, así como lo justo y lo injusto» (1253a) Esto, señala Aristóteles, estructura lo propio del hombre frente a los demás animales y es lo que convierte a la habitualidad habitable en algo fundamentalmente comunitario: la casa y la ciudad.

El lenguaje, frente a la voz o sonido, estructura un modo, no el único, pero uno de los más esenciales, de territorialización en la habitualidad y habitabilidad humana. Establece la limitación a través de un exceso o resto expresable a ese medio entorno precario reajustable activamente, así como también comunicable como el lenguaje, en cuyos modos rítmicos y armónicamente compues- 
tos se compone una suerte de cerco de habitabilidad a partir de modos habituales de expresión. Un modo, el ritornelo, en el cual el lenguaje actúa como una suerte de sucedáneo simbólico que pretende reinstaurar la territorialidad desajustada. Lenguaje como «resto cantable»" ${ }^{3}$.

Estos recursos de territorialización, y, en especial el lenguaje, se aparecen entonces como los modos comunitarios de nombrar y de comunicarse. Así visto, el lenguaje nombra, verbaliza y, por tanto, comunica en su propia condición activamente construida con el objeto adaptativo de concitar una suerte de sombra protectora y superpuesta ante el medio. En las palabras, pues, confluyen las cosas y, por ende, se habitúan a la circunstancia vital. Y así el mundo entorno se hace habitable comunitariamente.

Primariamente y por cuanto es conocimiento y estructura lógica del mundo, el lenguaje humano se constituye como arbolamiento en cuya seguridad se logra un límite a partir del cual desplegar los sentidos, las preguntas y los horizontes proyectivos. Desde esta circunstancia territorializada, desde este ámbito arbolado construido operatoriamente —no solo, pero también — a través del lenguaje nos reconocemos comunitaria e individualmente. El entorno cíclico y el territorio a él adscrito es nuestro lugar, nuestra comunidad y mundo simbólico. Solo en él y desde él damos sentido y nos sentimos. Unos versos del poeta extremeño Ángel Campos (2008: 329) lo dicen todo: «Por abrazar el aire me he llegado hasta aquí. Sólo por dar / sentido a una carencia y rebatir la soledad».

A este «sentirse», Heidegger lo describe como un modo de disponibilidad con la circunstancia. Una suerte de ajuste o «temple» respecto al territorio vital de la habitualidad habitable comunitaria. Se trata, de nuevo, de algo que desborda lo meramente psíquico o psicológico, y que también sucede en el animal una vez que este ajuste se ve alterado por la percepción o sensación, inminente o no, de un desajuste, un peligro en la habitualidad fáctica, una pregunta, extrañeza, dolor, desconfianza. Entonces, la circunstancia pierde su ritmo, su rima, su condición arbolada. Se desvirtúa la territorialización, la seguridad vital y el ritornelo. Se trata, por ello, de concebir la extrañeza, la duda o la pregunta, el hastío o el dolor no tanto como una condición ab ovo sino en cuanto una desconfianza a posteriori de lo habitual habitable.

Así, al notar dicho desajuste, el animal lanza el ritornelo, el canto, el sonido o el aviso. Y asimismo acude presto, de un modo innato, al límite del territorio, proyecta desde su cerco el sonido de peligro, advierte el desajuste y llama, y al llamar resitúa los límites advirtiendo el peligro de sus lindes.

Lo mismo sucede desde el logos. El encontrarse humano y comunitario de la circunstancia cercada y arbolada mediante la constante labor humana de territorialización habitable puede verse desajustado. Algo sucede: la pregunta,

3 Se trata de un poema de Paul Celan (1999: 215) sobre el que Valente (1991: 257) sitúa la esencia de la palabra poética. 
la admiración, la duda, el desasosiego o el mal. Es entonces, y solo entonces cuando, tras la facticidad lograda en el hábito de la habitabilidad humana se producen las desdimensiones, las inconmensurabilidades. Algo falla, se desencuentra. Algo llama... y siempre parece desde fuera del territorio. Y sin embrago, ¿en qué sentido comienza? ¿Hacia dónde se dirige? ¿Desde la nada, como si el mundo y su sentido se tuvieran ya a priori y ex nihilo de modo implícito? Por ello Chesterton (2013: 105) sostiene que más costoso y prístino que el preguntarse es el desajustarse a la convencida y fáctica inercia en la que se está para que la pregunta, movida por la perplejidad, comience.

De hecho, ¿por qué no concebir esa extrañeza, duda o pregunta, no tanto como algo que llama de antemano desde no se sabe qué más allá, cuanto más bien como una suerte de desconfianza de lo habitual y habitable? Quizás el dolor, la pesadumbre, el hastío, e incluso la muerte puedan así concebirse como décalages o desajustes que nos des-sitúan de nuestro apego confiante al ritmo vital de estar constantemente construido y reconstruido. E incluso más, por cuanto que ese mismo devenir, siempre interrogante y extraño, supone justamente la forma de recuperar activamente, por nuestra propia condición humana, una y otra vez, esa confianza nuevamente salvadora en la circunstancia.

IX. A este encontrarse fisiológico y anímico en el territorio cíclico habitual y habitable Heidegger, como decimos, lo llamó Stimmung.

La Stimmung es algo así como el temple ajustado del viviente (o Dasein) con su circunstancia. Su afinamiento y concordancia vitales. De hecho, el verbo alemán stimmen se aplica también en la afinación musical: el temple (Stimmung) determina (be-stimmen) el ajuste al sonido propicio y justo, al tono apropiado de ese encontrarse. Cuando esta Stimmung pierde su ritornelo, su ritmo habitual y habitable, parece surgir un desfase, una falta de afinación entre la circunstancia y el Dasein $^{4}$ que Heidegger resume fundamentalmente en dos estados: la angustia y el hastío. La reacción casi natural que busca restablecer este ritmo habitual y habitable del encontrarse en la circunstancia es la de generar o construir, con recursos humanos, un ritornelo sucedáneo. Volver, en la medida de lo posible, a través de acciones que nosotros llamaremos «supersticiosas», a la habitualidad segura de lo habitable, al ciclo ritmado y seguro del territorio. Así lo sostienen, de nuevo Deleuze y Guattari (2004: 298):

Un niño se tranquiliza en la oscuridad, o bien toca las palmas, o bien inventa una forma de caminar, la adapta a las rayas de la acera, o bien salmodia (...) Tra la la. Una mujer canturrea, - la oía canturrear dulcemente una melodía en voz baja. Un pájaro lanza su ritornelo.

${ }^{4}$ De entre otros lugares de la obra de Heidegger, sobre todo Ser y Tiempo \&29 (Heidegger, 2000: 151-157) 
Entonar una canción infantil, volver los pasos a través de una línea de sentido, silbar una melodía terruñera o tararear. E incluso, moldear una escultura, componer una música, escribir un poema. Modos de territorializar a través del logos un ritmo seguro, arbolado y determinado. Modos que parecen ser tan connaturales a nosotros como a los propios animales. La Stimmung se desajusta. El temple pierde su tono apropiado. El ritmo vital se priva - siempre de un modo extraño - de su rima. ¿No es justamente esto lo mismo que puede aplicarse a la composición del poema para Ossip Mandelstam?

Observé en su labor poética dos «suspiros de liberación» y no uno. El primero cuando aparecen en la estrofa o la línea las primeras palabras y otro cuando la palabra exacta expulsa los vocablos causales, intrusos. Entonces el proceso de escucharse a uno mismo, el proceso que abona el terreno para el desarreglo se desprende de su creador, deja de zumbar en su oído y atormentarle. El poseso se siente liberado. Ío, la pobre vaca, consigue huir del tábano (Mandelstam 2012: $123)$.

Este ritmo desajustado no obra de un modo meramente estético, a la manera de una simple cadencia sonora aledaña. Desde el propio modo de caminar, de auscultar los latidos del corazón o la respiración. Incluso, de un modo más genérico, desde el propio ritmo que se traspone a los períodos menstruales, a los ciclos de siembra y recolección, a las fases de la luna y las mareas, a los amaneceres y atardeceres... Se trata de un aspecto - como sostiene Octavio Paz (1972: 64-65) — ontológico o vital. La naturaleza del ritmo se eleva a órdenes existenciales, incluso de carácter místico-religioso: cada ritmo es una actitud, una imagen del mundo. Es imagen y sentido. Y no está fuera de nosotros mismos. Somos nosotros mismos. Y así, «el poema es mediación: por gracia suya, el tiempo original, padre de los tiempos, encarna en un instante».

X. De este modo, no ya el poema, sino eso que ha venido en llamarse «poetizar» se presenta bajo esta luz como un modo de restituir la Stimmung, el temple, a través de modos que podríamos llamar artísticos en su más puro sentido, pero que aquí llamamos también, supersticiosos.

En rigor, la conducta supersticiosa, establece un modo de sobre-ponerse o sobre-estar (super-stare o «estar sobre») no justamente en el sentido trascendente o disruptivo, sino sustitutivo, aledaño o sobrepuesto. Tampoco tomamos aquí el vocablo en el significado común de la creencia extraña o fe desmedida (DRAE, 22. ${ }^{\mathrm{a}}$ ed.), ni tampoco en el sentido conductual, como el que Skinner aplicaba a las palomas en sus conocidos experimentos ${ }^{5}$. Asimismo, Baruch

\footnotetext{
${ }^{5}$ A partir de 1948, el famoso psicólogo conductista B. F. Skinner llevó a cabo su experimento, introduciendo en su famosa caja a ocho palomas hambrientas que debían realizar ciertas acciones como accionar una palanca para lograr la comida. En sus conductas, Skin-
} 
Spinoza llama superstitio al error humano de tomar por bueno lo que produce tristeza y malo lo que da alegría, de tal manera que el supersticioso para el filósofo holandés es un hombre triste que erige su propia pena en virtud, su defecto en don, su fracaso vital en triunfo (Ética. IV, append. cap. 31).

Esperemos se nos permita tomar aquí el término «superstición» de una manera más literal. Se trata de un procedimiento artístico o artificial de recomponer miméticamente la realidad a partir de materiales como el lenguaje, que se constituyen en vicarios simbólicos de esta. Este modo - fundamento de toda producción artística - no es meramente gratuito, sino el único recurso alcanzable - como el canto para el pájaro- en orden a reinstaurar la Stimmung desajustada y, a su vez, un recurso sucedáneo a la realidad, sobrepuesto como un resto material, pero simbólico. Ya que, volviendo de nuevo a la etimología, en el símbolo se concitan (syn en griego, es decir, «con», así en sin-taxis: «com-posición») como en una conjuración, los desajustes para lanzarlos (en griego ballein). Porque, una vez proyectado el símbolo, este resitúa — como en un ritornelo - el territorio. Re-limita sucedánea y, así, simbólicamente, la territorialidad habitual y sus tiempos. Ese canto, el de la poesía, cuya «voz se obstina en conjurar el miedo: el de unas manos que buscan en lo hondo aplazar la muerte» (Campos, 2008: 406) y por el cual «tu cuerpo aún defiende el territorio» (Campos, 2008: 412) se construye como el único modo posible, y con los únicos recursos humanos posibles, de asegurar adaptativamente la habitualidad habitante.

A este procedimiento de imitación reconfiguradora, elaborada y virtuosa, afanosa y cotidiana, curtida por el hábito del hacer vital y productivo del hombre (y no solo por el «pensar» o la «pregunta» meramente «mentales» o «internos»), sin mayores aspavientos o ceremonias, los griegos lo llamaron mimesis.

El símbolo - decimos - es proyectivo en cuanto se lanza (ballein) desde el terruño de la habitualidad habitable para restituir, en la medida de lo posible (siempre en la medida de lo posible) la Stimmung, es decir, el temple vital ajustado. Tal vez por ello Pessoa (2002: 324) sostuviera en el Libro de desasosiego que «ya que no podemos conseguir belleza de la vida, busquemos al menos conseguir belleza del no poder conseguir belleza de la vida». «Estamos, sin más, —afirma Antonio Colinas (2007: 164) — ante un ser que ha dado con la verdad de la vida, al menos hasta donde un ser humano puede dar con esta verdad. Y nos la transmite en versos, y la fija en paradojas». La experiencia

ner comprobó como algunas procedían de modo extraño, utilizando procedimientos aledaños para llegar al refuerzo como rozar la cabeza a una de las esquinas de la caja o volar en sentido contrario a las agujas del reloj. Ello sucedía porque la paloma asociaba ese comportamiento, irrelevante en principio para alcanzar el refuerzo, con un mecanismo necesario de su conducta. A esta conducta, Skinner (1948: 168-172) la denominó «supersticiosa». 
simbólica se entiende así, desde estas coordenadas, como un lanzar o proyectar lo que está reunido o concitado (syn) en el momento propicio.

Como se sabe, el término symbolon se refería primitivamente a un objeto partido en varias porciones que dos o varias personas conservaban para, tras reintegrarlo en su todo primero, pudieran reconocerse como partes de él. Así lo relata el famoso pasaje de la Historia (libro VI, LXXXVI) de Heródoto de Halicarnaso el cual narra la historia de los hijos de un forastero de Mileto que había dejado la mitad de sus propiedades a su albacea Glauco en Esparta para que aquellos, en un futuro, lo recibieran. Con el dinero, Glauco obtuvo el símbolo como contraseña para que, cuando los hijos del milesio regresaran, pudieran reconocerlo aportando la otra parte.

Las metáforas, los colores y materiales tomados, de nuevo, como restos cantables en favor de la labor simbólica resultan, así pues, modos de superstición, ya que consisten en sobreposiciones artificiosamente producidas de reinstauración habitable. Modos artísticos - es decir, no naturales - lanzados, llevados o proyectados (phorein) más allá (como en metáfora meta-phorein: «llevar más allá») para reconfigurar el desajuste primario, en pos de su propia de-terminación fundante. «Al comprender algo lo transformamos en otra cosa, lo esquematizamos, lo conceptualizamos, y deja de ser lo que es» señala Ortega (2006: 254). Y sin embargo, ello resitúa (simbólicamente) mediante su artificio, la territorialidad, el espacio limítrofe de la circunstancia y el tiempo ritmado de la habitualidad y habitabilidad, que solo entonces se concibe como un modo simbólico del devenir adaptativo. De la misma manera que el ritornelo se ejecuta como un procedimiento mimético de reinstauración de lo habitual y habitable, así la metaforización a la que el arte de cualquier género, territorializa se realiza de un modo superpuesto, es decir humano, a la realidad desajustada misma que se pretende sucedáneamente reinstaurar en la medida de lo posible con los materiales que, en su misma labor, se conciben de modo sucedáneo o residual.

No se trata por tanto de un movimiento contra la «entropía» de la realidad o del lenguaje como señala el propio Ortega (2006: 247), para el cual la poesía, el poetizar «hace entrar en las cosas en un remolino y como espontánea danza». Y por ello, rompe el tempo vital: «el arte busca lo insólito, lo que rompe la costumbre, por eso es incómodo» (ibíd.: 249). Y asimismo, Octavio Paz (1972: 65) al afirmar que el poema contiene poesía cuando logra llevarnos a una peculiar experiencia, a saber, aquella que «es siempre un ir más allá de sí, un romper los muros temporales, para ser otro». No se trata tampoco del lenguaje como «morada en la que habita el Ser» (Heidegger 1970: 64), pues esta concepción del lenguaje resulta, una vez más, demasiado holgada y metafísica. Como una suerte de «experiencia» ad hoc por y desde un lenguaje vacuo, desinstalado. De hecho, esa misma «holganza» gratuita en su concepción parece análoga a la que Heidegger y su escuela sitúan en la base del lenguaje instrumentalizado, expresivo y unidimensionalmente referencial que el propio 
filósofo alemán denuncia en el positivismo lingüístico de los actuales modos tecnológicos y masivos de la comunicación de masas. Un lenguaje, de una u otra manera, establecido como una suerte de aledaño formal, por igual de modo abstracto en un «sí mismo» o autós metafísico como en su instrumentalización positiva y expresiva de modo utilitarista, tanto da.

Por ello, no parece esta — creemos - tanto una visión super-sticiosa, sino más bien super-ficial o excesivamente abstracta del lenguaje. En primer lugar porque el lenguaje en sí mismo es una práctica simbólica y a la vez irrenunciablemente adaptativa cuyos ritornelos se concretan en múltiples idiomas referencialmente desenclasados e inconmensurables en gran medida entre sí. Ello muestra hasta qué modo el lenguaje es un modo determinado y contingente adscrito a una circunstancia espacio-temporal propia.

XI. «Nada más falso — señala Ortega (2006: 255)— que suponer en el arte un subterráneo de la vida interior, un método para comunicar a los demás lo que fluye en nuestro sucedáneo espiritual». Por el contrario, la propia facticidad originaria del habitar genera su vez nuevos modos de desajuste en los que el propio vivir en la habitualidad y habilitabilidad se desarrollan. Se trata de esa «mudanza de la costumbre» de la que hablara Garcilaso y de la costumbre que llama a mudar y a reinstaurar de nuevo el ritmo vital a su justa afinación y temple. ¿Qué es la admiración de la que Aristóteles hablaba sino un desajuste? Así lo sostiene el propio Estagirita, el que de modo más canónico nos situó el verdadero espíritu de la pregunta: si existe la admiración — señala Aristóteles es justamente porque la realidad es un cosmos, una ordenación armónica y afinada en una habitualidad circunstancial, y no más bien un caos (Metafísica 982b: 5-15). Por ello, se rompe para recomponer, se proyecta para introyectar el cerco vital, asegurar recompositivamente o supersticiosamente, esto es, artísticamente la Stimmung desajustada o extrañada. Cuando este modo existencial queda re-conocido en su lugar y tiempo propicios, cuando este ritmo vital se reinstaura, esto es, cuando la habitualidad y habitabilidad quedan reapropiadas miméticamente en nuevas formas dentro del ciclo de ajustes y desajustes, entonces, tal vez, nos encontramos algo bello o verdadero como modos de reconsideración mundana. La Belleza y la Verdad entonces, como la recomposición, una vez más, fundante del territorio y tiempo habituales y habitables, y a su vez nuevo y supersticiosamente resituado por la labor humana a partir de los sucedáneos simbólicos. Es de nuevo esta desconfianza, tan humana y necesaria, hacia lo habitual habitable para volverlo a reinstaurar a través de lo más humano y necesario a lo que poder acceder. El mismo material que nos condiciona como condiciona al pájaro su canto; el lenguaje. No es tanto un modo de «iluminar el Ser» o un «dejar ser a las cosas», como propone Heidegger. Tal vez sea, más bien, un urgente y precario hacer lo que se puede, en la medida de lo posible. Tampoco se trata de presentar este «poetizar» como la he- 
roicidad de una «libertad creadora». Más bien consiste en una experiencia de retener reconvirtiendo lo más humilde y propio del lugar y el tiempo ante los embates mismos del devenir y de los cambios entorno. "Aquel que con sus ojos ha visto la Belleza / a merced de las Parcas ha sido abandonado». Así comienza, como se sabe, el famoso poema Tristán de August von Platen, poeta en el que Thomas Mann se inspiró para componer su célebre Gustav von Aschenbach de Muerte en Venecia.

¿No son estos versos justamente conocidos por proponer lo contrario a la Belleza (e igualmente, por qué no, podría decirse de la Verdad) como un ideal? ¿No significan Verdad y Belleza, según esta tesis, como el reconocimiento mismo de la contingencia y labilidad de un todo concreto y densamente fértil en su cierre finito determinado y determinante? E incluso, ¿no se colige una suerte de confiada y segura protección en la Belleza y la Verdad que se siente oportuna «aquí» y «ahora» la prueba misma de su contingencia y a la vez necesaria menesterosidad de la que parte y a la que llega?

Verdad y belleza no como un apósito intelectual, según señalaba Ortega más arriba. No en tanto un accidente posterior tras una pregunta inicial, creadora, proyectiva de mundo, sino más bien en cuanto el único modo de re-conocer la re-stitución del ritmo, el ri-tornelo, es decir, la Stimmung de la habitabilidad primigenia, el propio pulsar vital. La verdad y la belleza como reinstauración de ámbito vital seguro, prístino territorio, pero también definitivo, por cuanto es siempre último, esto es, consumatorio, así como de-finidor, o re-finidor en su nueva, retornada y definitiva instauración que establece de nuevo un territorio reconocible y habitable. No en vano, y tal vez a este respecto podemos retomar y reconfigurar desde aquí la tesis de Walter Benjamin cuando habla de «aura» o de Vicente Alexandre al titular uno de sus poemarios con el nombre de «Ámbito».

XII. No obstante, ¿en virtud de qué se reconoce, de nuevo, esa Stimmung que templa de nuevo, en su justo momento, el ritmo sensible e intelectual y que llamamos Belleza o Verdad? Platón es taxativo al respecto: la Verdad solo puede conocerse si ha sido previamente velada (lethe) en el ocultamiento al que el cuerpo, somete al alma, y del que aquel constituye su cárcel necesaria para existir en el mundo sensible. Por ello, todo conocimiento es reconocimiento, y la verdad «es el diálogo del alma consigo misma» (Teéteto 189e, Sofista 263e). Conocer la verdad, por tanto, es el recuerdo (anamnesis) de lo que, sin saberlo más que en el momento oportuno, había sido velado. Por eso, como sabemos, lo verdadero es alétheia, desocultamiento. Es el kairós de reconocimiento de la otra mitad del símbolo, y a la vez, de sí mismo. ¿Dónde habías estado que me faltabas? ¡Ahora lo sé! Solo ahora, pues, se nos da la nota justa según el patrón de la afinación que andábamos buscando y que solo se 
sabía perdido y buscado realmente al re-encontrarlo reinstauradoramente. Y entonces suceden la Verdad y la Belleza.

«El poema — señala Octavio Paz (1972: 64) — tiende a repetir y recrear un instante, un hecho o conjunto de hechos que, de alguna manera resultan arquetípicos». Recuperar o reinstaurar supersticiosamente una suerte de armonía que confluye, que rima con el lugar y el momento, el topos y el kronos. Acaso en ello, ni más ni menos, consista el lenguaje poético como un modo más — no el único - de la superstición reinstauradora: «El poema es tiempo arquetípico que se hace presente apenas unos labios repiten sus frases rítmicas. Esas frases rítmicas son lo que llamamos versos y su función consiste en recrear el tiempo» (Paz 1972: 65).

Pero ese arquetipo, ese patrón de afinación que da en el momento oportuno, la nota oportuna, esa intensa y profunda conjuración de un ámbito de nueva, fértil y segura disposición es reconocida porque se había perdido o desajustado. Por ello solo esa intensa experiencia de reconocimiento conjurado que suponen la Verdad y la Belleza tiene sentido si se parte de una factualidad o facticidad ya consagradas al tiempo y lugar determinados, una lealtad inercial inconsciente, no por oculta, sino al contrario, por habitual al ritmo de lo que siempre, y previamente está siendo.

En este mismo sentido Chesterton (2008: 139-146) propone una visión del mundo —en este caso con toda pertinencia, de carácter «supersticioso»— basada en los cuentos de hadas. El autor inglés concibe la poesía, y la literatura en general en tanto un modo simbólico de armonizar el mundo, como en un encantamiento, por el que el lenguaje ordena y reordena, deletreando cada elemento sucedáneamente a la realidad que quiere ser conjurada. Así en una nana o una fórmula mágica propia de los cuentos infantiles. Se trata, de nuevo, de formas activas del ritornelo que resitúan o re-territorializan la habitabilidad o habitualidad perdida, la cual, solo se concibe como activa y supersticiosamente ganada en esa misma extrañeza o desajuste y solo reconocida como tal a través de su pérdida. De este modo, señala el autor inglés, «todo cuanto significan la religión y la poesía es que, por un instante de revelación, recordamos lo que habíamos olvidado» (Chesterton, 2008: 140).

Pero no se trata, como decimos, de un reconocimiento respecto a una realidad ideal o trascendente, es decir, utópica. El poetizar como un modo más de la superstición artística no consiste en una creatio de lo ya a priori imposible de ser desde el Origen de los Tiempos, sino más bien lo conocido como siempre re-conocido (esto es, reinstaurado) a través de la pérdida o desajuste. En este sentido, insistimos, los modos supersticiosos (super) o metáforicos (meta) se inscriben ellos mismos en un modo de re-composición o re-situación sobre (y siempre sobre o tomando en cuenta) lo real. Este modo superreal o metarreal no es sino la mimesis de lo real y ha sido llamado tradicionalmente en griego poiein. 
A partir del tradicional análisis de Aristóteles al respecto, Paul Ricoeur (2001) en La metáfora viva recupera esta reinstauración simbólica del poiein como lo que el estagirita denomina «poner ante los ojos», es decir, «significar las cosas en acto» (Retórica III 1411b 24-25). Lo cual para Ricœur quiere decir considerar las cosas como no impedidas de advenir, verlas como lo que se concita y eclosiona en el proceso de reproducción (re-producere). Por ello, esta mimesis reproductiva, como se sabe, no es mera repetición idéntica, como no lo es ninguna repetición, sea esta artística o no. Por el contrario, la repetición significa justamente el modo rítmico del ritornelo establecido en la habitualidad y habitabilidad de la circunstancia y su intento supersticioso, esto es, elaborado y artístico de reinstaurarla.

En esa posibilidad humana de reinstauración o recomposición, en ese maximum, por el que los materiales que han de ser recompuestos se inscriben como un resto, huella o sucedáneo compositivo, es decir, un minimum a partir de lo real y a su vez formando parte misma de lo real; en ese resto desengranado del ritmo, de la Stimmung, y a partir de él, se mimetiza artísticamente la realidad. Y en esta recomposición vital, anímica, cognitiva, existencial o como la queramos llamar se encuentran justamente las categorías de lo bello o lo verdadero que no se antojan, por tanto, como una poderosa y libre Creación, sino más bien como el único modo, en la medida de lo posible, de reinstaurar vicariamente la realidad desajustada. Ni siquiera un paisaje natural, o una realidad bruta es verdadera o bella sino en cuanto, de modo más o menos elaborado, se percibe como re-compuesta activamente por el contemplador. Por eso la contemplación, como la producción no son fenómenos establecidos desde la férrea dialéctica entre lo activo y lo pasivo o lo interno y lo externo. Así lo es para Ricoeur la expresión aristotélica «significar en acto», pues ello también sería significar la potencia, en el sentido englobante que se dirige a toda producción de movimiento o de reposo para el contemplador, que en este punto, se identifica con el poeta: aquel que percibe la potencia como acto y el acto como potencia, es decir, que contempla la apertura reinstauradora y rememorante, aquel «principio inmanente que existe en los seres naturales sea en potencia, sea en entelequia que el griego denomina physis» (Ricoeur 2001: 408).

En este acto "poiético», el movimiento natural y la praxis humana del poetizar se disocian para Aristóteles, el cual adscribe el verdadero y pleno acto a esta última labor práctica (Metafísica, IX 1048b 18-36). Lo que importa esencialmente de esta tesis, señala Ricoeur (2001: 341), es el movimiento de «descentramiento» que opera Aristóteles, gracias al cual, «la energeia-dynamis orienta hacia un fondo de ser, a la vez potencial y efectivo, sobre el que se destaca el obrar humano». Con otras palabras, el obrar humano es el lugar de legibilidad de esta acepción del ser en cuanto distinta de todas las demás. Centralidad del obrar humano y descentramiento en dirección a un fondo de acto y de potencia. Estos son — señala Jaime Rubio (1999: 185) — rasgos constitutivos de una ontología del sí mismo. 
No solo la poesía, ni siquiera las demás manifestaciones artísticas son los únicos modos de reinstaurar esta habitabilidad y habitualidad, sino cualquier tipo de producción en el sentido más general y extendido del término, al que asimismo los griegos dieron el nombre de «arte» (techné). Se trata de establecer los modos de conducta elaborante como maneras de re-ordenar o re-componer sucedáneamente el material de la circunstancia. Desde la producción artística, pero también la artesanal, hasta los modos de cultura en su sentido más propiamente antropológico, es decir, los mitos, las narraciones genésicas y las religiones, pero también las cartografías, los nombres propios de cada uno de los diversos tipos de dientes, huesos y apéndices corporales por ínfimos que sean, los colores y sus innumerables variantes. Y asimismo las mediciones de temperatura, de espacio, tiempo, cantidad o volumen. La taxonomía botánica y zoológica de cualquier mínima o casi extinta especie, la nomenclatura de cada diverso estado de ánimo, sensaciones o fantasías. Las cartografías geológicas o políticas, los nombres de las calles, callejones, plazas y plazuelas. Las diversas maneras de nombrar juegos, como los naipes, y de establecer nombres para cada pieza. Los tecnicismos de cada disciplina por restringida que sea, las jergas sociales y grupales, los insultos ${ }^{6}$, la paremiología, los idiomatismos de

${ }^{6}$ ¿Por qué — por ejemplo- los actos más biológicos son los que más variopintos y metafóricos modos lingüísticos poseen? Las cuatro funciones vitales tradicionalmente asignadas al organismo con vida: nacer, crecer, reproducirse y morir, son precisamente las que toda cultura, sea cual fuere, ha imbuido de la más rica y múltiple simbología lingüística y ritual. Fijémonos en la tradición católica occidental: bautizos (nacimiento), comuniones (crecimiento), casamientos (reproducción), y funerales (muerte) están presentes en casi todas las prácticas culturales desde que el hombre llegó a la sociabilidad en el Neolítico. Asimismo, es muy probable que el lenguaje referido a dichas fases vitales sea el que más riqueza léxica y simbólica posea. Tomemos, por el ejemplo, el sexo: son innumerables y constantemente renovados los modos lingǘsticos de nombrar los atributos genitales masculinos o femeninos, los verbos, perífrasis y expresiones tan sutiles o burdas para referirse a la práctica sexual. Lo mismo podría decirse de la muerte o del comer. De hecho, la comida se encuentra presente en todas las reuniones sociales que celebran justamente los llamados «ritos de paso» (bodas, bautizos, comuniones...) pero también cualquier otra celebración ritual, por no decir la propia liturgia católica en cuya fase culmen, la eucaristía, el comulgante «consume» el cuerpo de Cristo, transubstanciado en el pan y el vino, por lo que el milagro espiritual y el condumio biológico, es decir, lo trascendente y lo fisiológico, lo allende exterior y lo interno orgánico se concitan en un proceso unificador de la mayor carga simbólica. José Ángel Valente (1991: 228-238) muestra, por ejemplo, como los modos cristianos de adoración de reliquias en forma de brazos, uñas o cabellos incorruptos significan esa unidad de lo más espiritual y simbólico con lo más residualmente corporal. Ya que hemos utilizado la bella, por escasamente usada, expresión «condumio», traemos a colación a este respecto la etimología que Covarrubias establece del término, vinculándolo con el término latino domus: «casa», «hogar». ¿No significa todo ello justamente la muestra de que el lenguaje, quizás de entre las demás otras prácticas o conductas propiamente humanas, significa el modo de hacer comprensible, y aún más, habitable y habitual el entorno vital del lugar y de los ciclos temporales? 
cada región o pueblo. Los tiempos verbales: pasados, simples o perfectos; los diversas maneras de mentar el presente (simple, continuo, histórico o gnómico, etc.), los futuros o potenciales en sus diversos modos y voces pasivas o activas. Y así también las leyes y normas más particulares o generales que la teoría y práctica científicas como la matemática o la física establecen en pos de garantizar una regularidad y predicción de los acontecimientos naturales pueden situarse a este respecto como modos poiéticos, es decir, lingüísticos y por tanto lógicos, de recomponer desde sobreinstancias metafórico-simbólicas el mundo entorno, sus leyes y sus normas que no son otras las que en suma garantizan la necesariamente humana habitualidad habitable y no tanto, quizás, y como se dice tan a menudo por cierta filosofía, un modo de dominación antropocéntrico o una racionalización controladora y rígida del mundo a través de un lenguaje egocentrista.

XIII. El desajuste, la extrañeza o la angustia fáctica que no sabíamos hacer presente se nos recompone a través del poetizar (como asimismo a través de otros modos de obrar) a la hora de efectuar el ritornelo. Y así la reconocemos.

Quizás por ello, el proceso de este re-conocimiento no parte tanto desde una idea del alma ascendida al mundo inteligible y olvidada, según Platón, sino más bien, desde el mismo desajuste de nuestra habitabilidad habitual que solo se ha hecho presente en su falta o arritmia vital o cognoscitiva, tanto da. Este «echar de menos» es reconocido, de entre otros modos, en su misma reinstauración supersticiosa a través de la producción artística. A partir del constructo simbólico por el cual hacemos comunitariamente habitable y habitual nuestra circunstancia se produce una suerte de desequilibrio o desafinamiento constantes en el devenir habitual mundano. Esta desdimensionalidad del orden habitable, establecida en el humano siempre desde un carácter simbólico o metafórico a través del logos precisa - como decíamos - de su misma reconfiguración simbólica para volver a la Stimmung, al temple vital adecuado. Es por ello que dicho material simbólico, inercialmente habitual, se antoja entonces asimismo como el único recurso de reinstauración de la Stimmung y por lo que esta se identifica, una vez retornada, como re-conocible. Dicho de otro modo, el propio desajuste, ad-viniente, extraño, doloroso y siempre temporal y propio del de-venir convierte al lenguaje (así como en otros materiales «artísticos») en el constructo consciente y precario, contingente y comunicador... único posibilitador de la reconfiguración simbólica del mundo entorno.

No se trata por tanto, insistimos, del lenguaje como «horizonte posibilitador de la presencia de los entes en el mundo», o como una apertura «desde la cual éstos son convocados a la significación» (Heidegger 1978: 125), sino más bien como el único y solo en su desajuste, supersticioso constructo de reinstauración de la habitabilidad habitual simbólica y siempre comunitaria. Un modo no 
tanto heroico o viático del «Ser» como tampoco meramente envasado en su mera utilidad. Como decíamos más arriba, se trata más bien de una precariedad, un desvalimiento de fondo en todo el que concibe o experimenta algo bello, algo verdadero. Los dioses que no limitan sus miembros a una proyección delimitada, que no sufren la contingencia del aquí y ahora, no lo necesitan, como no necesitan amar. De hecho, tal vez el fundamento de un poema verdadero - de un verdadero poema- se sitúe en esta suerte de angostura lingüística, en la experiencia vicaria y restante el lenguaje como lo único posible y necesario para reinstaurar, siempre de un modo supersticioso, pero el único viable, la territorialidad habitable y habitual.

Y cuando ello sucede, algo entonces nos acoge, un aura, un ámbito... y nos reconocemos. A este encontrarse o reencontrarse oportunamente desde una proyección simbólica que restablezca definitivamente el territorio habitable y habitual, es decir, a esta armonía conjugada mediante la labor artística humana podemos llamarlo - decimos - con la gran, necesaria pero también humilde, y contingente manera supersticiosa de la Verdad y la Belleza. Así lo sostiene Yves Bonnefoy (1995: 185):

Contra las retóricas de nuestro tiempo, recurso de espíritus que sienten despecho o temor por el cielo vacío, es preciso recordar — es el primer paso- esa voluntad de experimentar, de unir, de escuchar igualmente el gozo del instante que la amenaza de la hora, de existir tanto como hablar, que es buscar, de hecho, reconocer, y para alcanzar el fondo. La función de la poesía, decía yo, es celebrar. Esto significa: consagrarse al lugar, al instante, incluso si no son nada, pues en su fondo está el todo, que aún no es nada tampoco, que es la nada, pero, cómo decirlo, que tiene arranques de música desde el momento en que se lo ha aceptado. En el corazón de lo vivido y de lo reunido el río, siempre. Pero esta vez o por fin, todo claridad y transparencia.

Asombrarse del mundo y a la vez sentirlo como hogar. Y aún más, que esa extrañeza sea más extraña a medida que el mundo habitable se va haciendo más comprensiblemente habitable. Las grandes preguntas y las grandes rupturas en la Weltanschauung simbólica del entorno no suceden sino con el objeto potencial de preservar el territorio, habitar de nuevo en lo comprensible, fijar los límites, marcar la majada, preservar. Una labor humilde, precaria y contingente, tan natural en sus diversos estratos, tanto en el animal como en el hombre, que se lleva a cabo en este último activamente (en la medida de lo posible) a partir de materiales, que también, y sobre todo son, en gran medida, simbólicos o artísticos.

Tal vez entonces la Verdad y la Belleza solo se conciban como las dos partes, los dos sentidos contradictorios y, en ello, precisamente recíproca y dialécticamente hermanados a la vez entre sí: extrañamiento y habituabilidad habitable. Lo cierto es que Verdad y Belleza a este respecto solo pueden im- 
bricarse — tomando la famosa ecuación de Keats 7 - si son situadas en la confianza respecto al reconocimiento que el lenguaje, y no solo el lenguaje, sino la labor de recomposición instauradora de territorio habitable a través del poetizar logra, de modo necesariamente humano, el temple propicio y apropiado de la habitualidad y habitabilidad que recupere la armonía simbólica y posibilitadora del ritmo vital. No se trata, entonces, de un proceso creador, sino vital y supersticiosamente adaptativo propio de todo habitar humano.

Fidelidad al hombre y a su lúcida esperanza de serlo totalmente; fidelidad a la tierra donde hunde sus raíces más profundas, fidelidad a la palabra que en el hombre es capaz de la verdad última de la sangre, que es también verdad del alma (Campos 1985: 88).

Los dos pedazos del symballon, esto es, la moneda simbólica re-conocen en su mutua y esencial afinación o reinstauración, por decir litúrgica, un lugar y tiempo «en verdad justo y necesario». Así se sitúan, supersticiosamente reconstruidos, como «nuestro deber y salvación» ${ }^{8}$ la inmanencia de nuestros límites humanos y los de nuestro material circundante para que, por ende, y de nuevo, «todo lo mudará la edad ligera / por no hacer mudanza en su costumbre» (Garcilaso, 2008: 84).

\section{BIBLIOGRAFÍA CITADA}

Aristóteles (1998). Metafísica, trad. Valentín García Yebra. Madrid: Gredos.

Aristóteles (2000). Política, trad. Pedro Simón Abril. Madrid: Gredos.

Bonnefoy, Yves (1995). «Paul Celan», Nombres. Revista de Filosofía. 6, pp. 183-188.

Campos Pámpano, Ángel (1985). Los nombres del mar. Poesía portuguesa 1974-1984. Mérida: Editora Regional de Extremadura.

Campos Pámpano, Ángel (2008). La vida de otro modo (Poesía 1983-2008). Madrid: Calambur.

Casado, Miguel (2009). La experiencia de lo extranjero. Ensayos sobre poesía. Barcelona: Galaxia Gutenberg-Círculo de Lectores.

Celan, Paul (1999). Obras Completas, trad. José L. Reina Palazón. Madrid: Trotta.

Chesterton, Gilberth K. (2008). Lectura y locura, trad. Victoria León. Sevilla: Espuela de Plata.

Chesterton, Gilberth K. (2010). Autobiografia, trad. Olivia de Miguel. Barcelona: Acantilado.

Chesterton, Gilberth K. (2013). Ortodoxia, trad. Miguel Temprano García. Barcelona: Acantilado.

\footnotetext{
${ }^{7}$ Beauty is truth, truth beauty, - that is all / Ye know on earth, and all ye need to know. «Ode on a Grecian urn» (Keats 1970: 43)

8 Pasajes del Prefacio de santa María Virgen I, en la misa católica.
} 
Colinas, Antonio (2007). «La poesía trascendente de Pessoa-Caeiro», en Ángel Marcos de Dios (ed.), Aula ibérica. Actas de los congresos de Évora y Salamanca (2006-2007). Salamanca: Ediciones de la Universidad de Salamanca, pp. 160-168.

Deleuze, Guilles., Guattari, Félix (2004). Mil mesetas. Capitalismo y esquizofrenia, trad. José Vázquez Pérez y Umbelina Larraceleta. Valencia: Pre-textos.

Földényi, László (2008). Melancolía, trad. Adan Kovacsics. Madrid: Círculo de Lectores-Galaxia Gutemberg.

Garcilaso de la Vega (2008). Poesía Castellana Completa. Madrid: Cátedra.

Guillén, Jorge (2010). Aire Nuestro. Barcelona: Tusquets.

Lynch, Enrique (2010). «La felicidad de las mónadas», en Aranzueque, Gabriel (ed.), Ontología de la distancia. Madrid: Abada, pp. 75-98.

Heidegger, Martin (1970). Carta sobre el Humanismo, trad. Rafael Gutiérrez Girardot. Madrid: Taurus.

Heidegger, Martin (1978). ¿Qué significa pensar?, trad. Raúl Gabás. Buenos Aires: Nova.

Heidegger, Martin (1989). Escritos sobre la universidad alemana, trad. Ramón Rodríguez. Madrid: Tecnos.

Heidegger, Martin (2000). El ser y el tiempo, trad. José Gaos. México D. F.: Fondo de Cultura Económica.

Heidegger, Martin (2010). «¿Para qué poetas?», en Caminos de bosque, versión de Elena Cortés y Arturo Leyte. Madrid: Alianza.

Heródoto (2001). Historia. Libros V-VI, trad. y notas de C. Schrader, revisada por M. ${ }^{a}$ E. Martínez-Fresneda. Madrid: Gredos.

Jonas, Hans (1998). Pensar sobre Dios y otros ensayos, trad. Ángela Ackermann. Barcelona: Herder.

Keats, John (1970). Lamia, Isabella, The Eve of St. Agnes, and Other Poems. Toronto: Scholar Press.

Kirk, G. S., Raven, J. E. y Schofield (1994): Los filósofos presocráticos, trad. Jesús García Fernández. Madrid.

Mandelstam, Nadiezhda (2012). Contra toda esperanza, trad. Lydia Kúper. Barcelona: Acantilado.

Ortega y Gasset José (2006). Obras Completas VI. Madrid: Taurus-Fundación Ortega y Gasset.

Paz, Octavio (1972). El arco y la lira. México D. F.: Fondo de Cultura Económica.

Pessoa, Fernando (2002). El libro del desasosiego, trad. Perfecto Cuadrado. Barcelona: Acantilado.

Platón (2006). Diálogos V. Parménides, Teéteto, Sofista, Político, trad. M. ${ }^{a}$ Isabel Santa Cruz, Álvaro V. Campos y Néstor L. Corder. Madrid: Gredos.

Porchia, Antonio (1975). Voces. Buenos Aires: Hachette.

Ricoeur, Paul (2001). La metáfora viva, trad. Agustín Neira. Madrid: Trotta.

Rilke, Rainer M. (1998). Elegías a Duino. Sonetos a Orfeo, trad. Eustaquio Barjau. Madrid: Cátedra.

Rimbaud, Arthur (1995). «Cartas del Vidente», en Iluminaciones; Cartas del Vidente, trad. Xoán Abeleira Álvarez. Madrid: Hiperión, pp. 100-131.

Rubio A., Jaime (1999). «Libertad y Potencia en Spinoza», Universitas Philosophica. 32, pp. 183-198.

Scholem, Gerschom (1995). La Cábala y su simbolismo, trad. José A. Pardo. Madrid: Siglo XXI.

Serna Arango, Julián (2009). Somos tiempo. Crítica a la simplificación del tiempo en Occidente. Barcelona: Anthropos. 
Skinner Charles R. (1948). «"Superstition” in the pigeon», Journal of Experimental Psychology. 38, pp. 168-172.

Valente, José A. (1974). «Ensayo sobre Miguel de Molinos», en Miguel de Molinos, Guía espiritual; seguida de la Defensa de la contemplación. Barcelona: Barral.

Valente, José A. (1991). Variaciones sobre el pájaro y la red. Barcelona: Tusquets.

Vallejo, César (1998). Poesía Completa. Madrid: Akal.

Fecha de recepción: 27 de julio de 2015.

Fecha de aceptación: 13 de septiembre de 2016. 